Sección Tres: Experiencias, reseñas, debates e informes

Educación y Exclusión social

\title{
Un recorrido por el Sistema Institucional en el ámbito de la violencia de género ${ }^{1}$
}

A travel of the Institutional System in the field of gender violence

\author{
Tania Martínez Romero \\ Universidad de Cádiz \\ as.hela@hotmail.com
}

Esta aportación trata sobre las experiencias y conocimientos adquiridos referentes al Trabajo Fin de Grado que he realizado, titulado "Propuestas de Mejora al Sistema Institucional en el Ámbito de la Violencia de Género", en el cual partía de una idea que ha estado vigente desde que estaba en primero de carrera.

Este trabajo trata de analizar algunas medidas y recursos en el ámbito de la violencia de género, así como la segunda victimización, dado que tras 14 años desde la entrada en vigor de la Ley 1/2004, de 28 de diciembre, de Medidas de Protección Integral contra la Violencia de Género y de las numerosas respuestas institucionales y campañas de sensibilización en este contexto, seguimos encontrando con una gran cifra de mujeres que sufren violencia de género. Por lo que, quizás, es importante mirar otras perspectivas e indagar en el tema. Para ello, se consultó bibliografía de fuentes primarias y se realizaron 7 reuniones con diferentes agentes sociales implicados, los cuales fueron: teniente de alcaldesa de Igualdad, Acción Social y Medio Rural, un mando de la Guardia Civil, jefe de la Policía Local, Policía Nacional de la Unidad de Atención a la Familia y Mujer (UFAM), juez del Juzgado de Violencia sobre la Mujer, fiscal especializado en Violencia de Género, psicóloga del Centro Asesor de la Mujer. Tras ello, se analizaron cada una de las reuniones. Cabe señalar que redactaron propuestas de mejora para el ámbito institucional en lo referente a la violencia de género, específicamente para la orden de protección, el Servicio Telefónico de Atención y Protección a las víctimas de violencia de género (ATENPRO), el derecho a la información y

${ }^{1}$ Recibido: 19/05/2017 Evaluado: 23/06/2017 Aceptado: 25/06/2017

No 7, 2019. Página $\mid 256$ 
automatización y a la segunda victimización. Por último, se llegaron a unas conclusiones, cuya conclusión global se menciona al final del presente artículo.

Las entrevistas proporcionaron puntos de vista en los que inicialmente no se había reparado y facilitaron la reflexión más profunda sobre el sistema Institucional en el ámbito de la violencia de género y su forma de funcionamiento. En lo que se refiere a la victimización secundaria, fue sorprendente encontrar a personas entrevistadas que afirmaban su existencia y la veían como un problema, donde primaba la prevención y la educación de los profesionales que tratan con las víctimas con el objeto de evitar que tengan un perjuicio añadido y, por ende, la exclusión de las mismas.

El Trabajo Fin de Grado realizado me ha ayudado a empoderarme en el ámbito del Trabajo Social y como persona, ya que ha aportado nuevas perspectivas y ha ampliado las que en un principio ya tenía, así como adquirir conocimientos, tanto por la bibliografía proveniente de fuentes primarias como el conocimiento de las circunstancias de cada una de las personas entrevistadas.

Por último, la frase final del Trabajo Fin de Grado, recoge la idea desarrollada a lo largo del mismo y en este mismo artículo, y esta es que se las han llamado "víctimas" a quienes en realidad han sido supervivientes. Esta es, sin duda una conclusión esclarecedora. 